\title{
Sinus Bradycardia Rare but Expected Complications of Chemo Regimen Involving Dexamethasone: Case Report
}

\author{
Jinqiong Li' ${ }^{1}$, Mohammad Arphan Azaad2*, Yongping Li2 ${ }^{2}$, Qiurong Zhang² \\ ${ }^{1}$ Department of Clinical Medical College, Dali University, Dali, China \\ ${ }^{2}$ Department of Hematology, Affiliated Hospital, Dali University, Dali, China \\ Email:173844678@qq.com, ${ }^{*}$ arphanazaad@hotmail.com, ${ }^{*}$ yongping_li@hotmail.com
}

How to cite this paper: Li, J.Q., Azaad, M.A., Li, Y.P. and Zhang, Q.R. (2017) Sinus Bradycardia Rare but Expected Complications of Chemo Regimen Involving Dexamethasone: Case Report. Open Journal of Blood Diseases, 7, 47-50.

https://doi.org/10.4236/ojbd.2017.71005

Received: February 27, 2017

Accepted: March 28, 2017

Published: March 31, 2017

Copyright $\odot 2017$ by authors and Scientific Research Publishing Inc. This work is licensed under the Creative Commons Attribution International License (CC BY 4.0).

http://creativecommons.org/licenses/by/4.0/

\begin{abstract}
Weight gain, Osteoporosis, Glucose intolerance, Hypertension, and Cataract are the common complications associated with Dexamethasone. However, here we report a case of Multiple Myeloma who received chemotherapy involving Dexamethasone. Although this patient has no previous comorbid cardiac condition, he developed Sinus Bradycardia during the latter part of chemo regimen. Ironically Sinus Bradycardia was asymptomatic in these cases. The exact mechanism of how Dexamethasone causes Sinus Bradycardia is yet not properly understood, and some of the possible mechanisms of Dexamethasone causing Sinus Bradycardia have been postulated below.
\end{abstract}

\section{Keywords}

Dexamethasone, Sinus Bradycardia, Multiple Myeloma

\section{Case Reports}

A 61-year-old patient had persistent nonradiating chest pain of 2 years. This patient had no previous history of Hypertension, Coronary Artery Disease or any other cardiovascular disease. ECG, Complete Blood Count was within normal limits; on the basis of persistent ribs pain bone marrow aspiration and biopsy were done and detailed study revealed Multiple Myeloma. Chemotherapy was planned under VAD regimen. Vincristine: $0.7 \mathrm{mg}$ (day 1 to day 4), Doxorubicin: $16 \mathrm{mg}$ (day 1 to day 4), Dexamethasone: $40 \mathrm{mg}$ (day 1 to day 4, day 9 to 12, day 17 to day 20). After completion of the first cycle of chemotherapy, the patient had no tolerance-related complaints. So the second cycle of chemotherapy was given without any adjustment. The second cycle of chemotherapy was also uneventful. During the third cycle of chemotherapy the patient's heart rate was 
noted to be 58/minute. ECG was taken which revealed Sinus Bradycardia, rate being 45 per minute. After the withdrawal of Dexamethasone, the patient's heart rate returned to normal.

A 51-year-old female presented with recurrent back and ribs pain. The patient had no previous history of Hypertension, Coronary Artery Disease or any other cardiovascular disease. ECG, Complete Blood Count was within normal limits. $\mathrm{X}$-ray of Lumbo-sacral region shows suspicious punched-out lesion. Combined with Bone Marrow study, a diagnosis of Multiple Myeloma was made. Chemotherapy was planned with Bortezomib along with VAD regimen. Bortezomib: 2 $\mathrm{mg}$ (day 1, 4, 8, 11), Vincristine: $0.5 \mathrm{mg}$ (day 1 to day 4), Dexamethasone: $30 \mathrm{mg}$ (day 1 to day 4), Doxorubicin: $10 \mathrm{mg}$ (day 1 to day 4). The patient had uneventful three cycles of chemotherapy. During the fifth cycle of chemotherapy the patient's heart rate began to decrease. ECG was taken which revealed Sinus Bradycardia with heart rate being 48/minute. Dexamethasone was kept on hold and after 2 days the patient's heart rate returns to normal limits.

\section{Discussion}

Multiple myeloma is a neoplastic plasma-cell disorder that is characterized by clonal proliferation of malignant plasma cells in the bone marrow microenvironment, monoclonal protein in the blood or urine, and associated organ dysfunction as shown in Figure 1. It accounts for approximately $1 \%$ of neoplastic diseases and $13 \%$ of hematologic cancers. In Western countries, the annual age adjusted incidence is 5.6 cases per 100,000 persons. The median age at diagnosis is approximately 70 years; $37 \%$ of patients are younger than 65 years, $26 \%$ are between the ages of 65 and 74 years, and 37\% are 75 years of age or older. Generally Plasma cells secrete Polyclonal Immunoglobulin however, in cases of Multiple Myeloma Plasma Cells secretes Monoclonal Immunoglobulin's. In recent years, the introduction of autologous stem-cell transplantation and the availability of agents such as thalidomide, lenalidomide, and bortezomib have changed the management of myeloma and extended overall survival. In patients presenting at an age under 60 years, 10-year survival is approximately $30 \%$ [1].

Corticosteroids treat a variety of conditions, mostly used for its glucocorticoids effects that suppress inflammation and natural immunity with the mostly unintended adverse side effects of breakdown of fats, carbohydrates, and proteins.

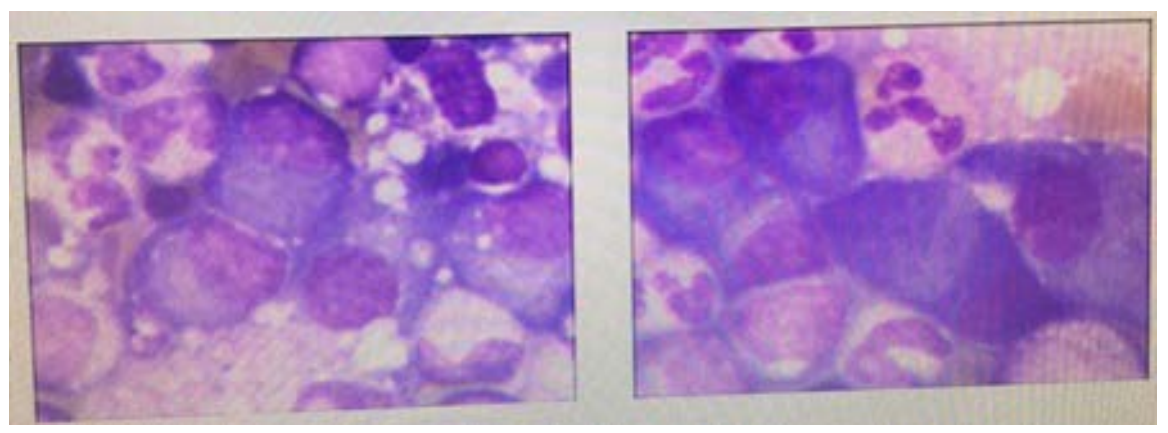

Figure 1. Bone marrow image of high plasma cells in bone marrow. 
Steroids are also used for its mineralocorticoids effects that regulate the balance of salt and water in the body. The adverse effects of steroids are many and varied, mostly focus on endocrinological system causing weight gain, changes in lipids, elevations in serum sugar level, retention on salt and water as well as immunological affect causing an increases risks of infections. Corticosteroids induced bradycardia is rare condition and was first documented in 1986 [2].

Corticosteroid induced bradycardia can be asymptomatic or symptomatic. Asymptomatic bradycardia is more common than symptomatic bradycardia. Tachy- or brady-arrhythmias occur in $1 \%-82 \%$ of adults and children taking steroids. Intravenous methylprednisolone (IVMP) in adults was reported to cause atrial fibrillation, supraventricular tachycardia, ventricular tachycardia, bradycardia, asystole and even death. In children, such adverse reactions are less frequent. They were reported with various types, routes, and dosages of steroids. Ueda et al reported atrial fibrillation in two children within 24 hours after receiving a pulse therapy of IVMP, while bradycardia developed in $82 \%$ of children who received IVMP for refractory Kawasaki disease. Dexamethasone was reported to cause bradycardia and hypertension in premature infants treated for bronchopulmonary dysplasia. It has been suggested that alteration in the baroreceptor reflex could explain the association with the change in blood pressure seen in dexamethasone treated patients. However, it is also possible that bradycardia occurs as an idiosyncratic reaction to dexamethasone similar to what was described by Lucas et al. [3]. Bradycardia occurring as a side effect of Dexamethasone are usually asymptomatic. If bradycardia persists despite use of repeated atropine and patient has typical symptoms of dizziness have episode of Loss of Consciousness in such scenario patient requires Temporary Pacemaker.

Dexamethasone is a long acting steroids, its biological half-life being (36 to 54 hours), possible side effects include Tachycardia and Congestive Heart Failure. With these cases we can also assume that possible side effects may include Sinus Bradycardia. Significant hemodynamic alterations secondary to short term steroids have been reported. Bradycardia (defined as a heart rate less than 60 BPM) has been described with high dose pulse methylprednisolone therapy used in autoimmune diseases. It has also been described following short term oral prednisone use. Cardiac arrhythmias as a result of dexamethasone use have been less frequently described and primarily involve pediatric patients [4].

In our part of the world the incidence of Multiple Myeloma is typically manifest around $4^{\text {th }}$ to $6^{\text {th }}$ decades of life. Raised Serum Calcium along with punched out bone lesion is a common finding in Multiple Myeloma patients. Mortality among Multiple Myeloma cases is usually due to Chest Infection, Urinary Tract Infections which may lead to refractory sepsis. Recent development of advanced Chemo regimen along with proper supportive care has seen a lot of cases of Multiple Myeloma achieving Complete Remission.

\section{Conclusions}

Bradycardia should be considered as expected side effect of Dexamethasone 
therapy.

Dose reduction of Dexamethasone or in some scenarios discontinuation of Dexamethasone on chemo regimen must be considered.

Bradycardia typically manifests on the latter part of chemo regimen (involving Dexamethasone).

\section{References}

[1] Palumbo, A. and Andersen, K. (2011) Multiple Myeloma, Medical Progress a Review Article. New England Journal of Medicine, 364, 1046-1060. https://doi.org/10.1056/NEJMra1011442

[2] Hasan, A.Q. and Al-Khazraji, A. (2012) Corticosteroids-Induced Bradycardia: A Case Report \& Literature Review. Arab Journal of Nephrology and Transplantation, 5, 47-49.

[3] Al Shibli, A., Al Attrach, I. and Hamdan, M.A. (2012) Bradycardia Following Oral Corticosteroid Use: Case Report and Literature Review. Arab Journal of Nephrology and Transplantation, 5, 47-49.

[4] John, P.R., Khaladj-Ghom, A. and" Still, K.L. (2016) Bradycardia Associated with Steroid Use for Laryngeal Edema in an Adult: A Case Report and Literature Review. Case Reports in Cardiology, 2016, Article ID: 9785467, 5 p.

Submit or recommend next manuscript to SCIRP and we will provide best service for you:

Accepting pre-submission inquiries through Email, Facebook, LinkedIn, Twitter, etc. A wide selection of journals (inclusive of 9 subjects, more than 200 journals) Providing 24-hour high-quality service User-friendly online submission system Fair and swift peer-review system Efficient typesetting and proofreading procedure Display of the result of downloads and visits, as well as the number of cited articles Maximum dissemination of your research work

Submit your manuscript at: http://papersubmission.scirp.org/

Or contact ojbd@scirp.org 